\title{
Reestruturação do serviço público na era do trabalho flexível
}

\author{
Lícia Helena de Oliveira Medeiros' \\ Paulo Gracino Junior ${ }^{2}$
}

\begin{abstract}
Resumo: Esta pesquisa tem como objetivo central analisar os efeitos da privatização do sistema público de saúde no cotidiano do trabalho dos servidores públicos estaduais da saúde do Rio de Janeiro, suas implicações objetivas e subjetivas nas dimensões sociais, políticas e trabalhistas. O eixo central é compreender a construção do indivíduo pela nova atividade que realiza, a relação e a vivência com o novo trabalho e analisar os sentidos e significados atribuídos pelos atores ao atual contexto de ser trabalhador da saúde pública. Tal temática tem sido foco de constantes debates, principalmente entre os espaços acadêmicos, sindicais e setores públicos. O trabalho de campo foi realizado entre os anos de 2014 e 2017, e os atores sociais analisados formam o grupo de profissionais dispensados das unidades de saúde e encaminhados para realizar serviços burocráticos na Superintendência de Perícia Médica e Saúde Ocupacional do Rio de Janeiro. A observação participante possibilitou explorar as diferentes retóricas que cercam as principais questões que envolvem os atores sociais, as relações sociais e a precarização do trabalho. Para a coleta de dados, foram utilizadas, como base empírica, entrevistas de vinte e um participantes, que vivenciam a precarização das suas atividades profissionais. Eles falaram sobre satisfação pessoal; independência; autonomia; identidade; valor; relacionamento; e inserção e representação social. As análises dos dados denotam que as narrativas se entrelaçam e, do início ao fim da pesquisa, repetem as mesmas questões e expõem o mesmo conflito: o sofrimento, as incertezas, o medo, a vivência das atitudes hostis, e a flexibilização das atividades profissionais, tanto no micro como na macroestrutura.
\end{abstract}

Palavras-chave: Precarização do trabalho. Privatização. Identidade profissional. Serviço público.

\footnotetext{
1 Doutora em Sociologia pelo Instituto Universitário de Pesquisa do Rio de Janeiro (IUPERJ) e graduada em Terapia Ocupacional pela Sociedade Augusto Motta (1994). Professora do IFF-RJ. E-mail: licia.medeiros@ifrj.edu.br

2 Pós-DoutoremSociologiaIFCS-UFRJ, doutoremSociologiaPPCIS/UERJ, mestreemCiências Sociais UNIRIO e graduado em História UFOP. Professor do Programa de Pós-Graduação em Sociologia Política do IUPERJ. E-mail: paulogracino@iuperj.br
} 


\title{
Restructuring public service in the flexible working age
}

\begin{abstract}
This research has as main objective to analyze the effects of the privatization of the public health system in the daily work of the state public health workers in Rio de Janeiro, its objective and subjective implications in the social, political and labor dimensions. It's central axis is to understand the construction of the individual through his/her new activities, their relations and perception of the new work, and to analyze the senses and meanings attributed by the actors to the current context of being a public health servant. This theme has been the focus of several studies, especially in academic, trade union and public sector areas. The field work was conducted between the years 2014 and 2017 and the social actors analyzed form the group of professionals that were put aside from health units to be transferred to bureaucratic services at Superintendence of Medical Expertise and Occupational Health of Rio de Janeiro. Participant observation has made it possible to explore different rhetorics surrounding the main issues involving the social actors, their social relations and the precariousness of their work. To gather data, twenty one participants composed the empirical basis. They are living the precariousness of their professional activities and talked about personal satisfaction; independence; autonomy; value; relationships; and social inclusion and representation. Data analysis show that narratives are intertwined, and, from the beginning to the end of the research, they repeat the same questions and expose the same conflict: suffering, uncertainties, fear, experiencing hostile attitudes, and the flexibilization of professional activities, in micro as well as in macrostructure.
\end{abstract}

Keywords: Work precariousness. Privatization. Professional identity. Public Service. 


\section{Introdução}

Este artigo tem o objetivo de contribuir para as reflexões sobre o impacto da privatização do sistema estadual de saúde do Estado do Rio de Janeiro no cotidiano do trabalho dos servidores públicos, bem como abordar suas implicações objetivas e subjetivas. Mais especificamente, analisamos o grupo de profissionais dispensados das unidades de saúde e encaminhados para realizar serviços burocráticos na Superintendência de Perícia Médica e Saúde Ocupacional do Estado do Rio de Janeiro. Neste sentido, o eixo central é compreender a construção do indivíduo pela nova atividade que realiza, a relação e a vivência com o novo trabalho e analisar os sentidos e significados atribuídos pelos atores ao atual contexto de ser trabalhador da saúde pública.

Desta forma, este trabalho, ainda que não trate especificamente dos impactos da terceirização e da consequente precarização do trabalho no setor da saúde no Rio de Janeiro nas políticas de promoção de saúde do Estado, aborda um processo correlato e importante para compreensão da falência do sistema público de saúde do mesmo. Como desejamos que fique claro mais adiante, o processo de implantação das Organizações de Saúde, que hoje são uma tônica no sistema de saúde fluminense, tem efeitos que vão para muito além da precarização do atendimento primário em saúde, como assistimos diariamente, outrossim, impactam sobremaneira a subjetividade dos trabalhadores em saúde, ao alterarem de forma fundamental o significado que eles atribuem ao trabalho, seja através da precarização promovida pela terceirização, ou pelo desvio de função, alvo central deste artigo.

Porém, antes de prosseguirmos, acreditamos ser interessante discorrermos algumas linhas sobre o expediente metodológico de que lançamos mão para efetuar a pesquisa, que se baseou em uma abordagem qualitativa, com observação participante, por intermédio de procedimento do estudo de campo, dividido em três etapas: 1) fase exploratória; 2) trabalho de campo e 3) análise e tratamento do material empírico. Definiram-se os seguintes critérios de inclusão para a presente análise: terem tempo de serviço superior a 10 anos com cargo efetivo de servidor público da saúde do estado do Rio de Janeiro e terem sido deslocados das suas unidades hospitalares e encaminhados para uma instituição administrativa (Superintendência de Perícia Médica e Saúde Ocupacional- SPMSO).

Foram três anos de observação participante (2014-2017) acompanhando as novas atividades laborais exercidas pelos participantes. Esta pesquisa teve como núcleo de interesse investigativo as representações, sentidos e significados atribuídos que um grupo de servidores públicos da saúde possui acerca da privatização do sistema, da identidade, do valor, da autonomia e da satisfação profissional. Essas foram as cinco categorias analisadas a respeito da dimensão organizacional do trabalho, sinalizadas na fase exploratória e durante todo o percurso no campo.

Inicialmente, com o objetivo de aproximação e aprender sobre os sujeitos da pesquisa, foi aplicado um questionário sociodemográfico tendo como alvo cento e cinco (105) participantes, entre eles: Assistentes Sociais, Enfermeiros, Fisioterapeutas, Médicos, Técnicos e Auxiliares de Enfermagem. Foram abordadas questões relativas a gênero, idade, estado civil, prática religiosa, escolaridade, residência, filiação, rendimento familiar, profissão que ocupa no Estado, tempo de serviço, unidade em que trabalha, horas por semanas trabalhadas, atividade em outra unidade hospitalar, treinamentos já recebidos, atividades realizadas fora do trabalho e horas de trabalho total. 
Foi percebida uma divergência de acessibilidade cultural, da prática religiosa e de classes sociais significativas entre os indivíduos, desde a moradia, principalmente nas zonas norte e sul, para os especialistas, e a baixada fluminense para os auxiliares e técnicos de enfermagem (que não dispõem de transporte particular para realizar as atividades de lazer e cultural). Para alguns desses servidores, as férias significam fazer plantões extras em outras unidades, principalmente nos hospitais federais.

Para complementar a organização dos dados foram realizadas, nos anos de 2016 e 2017, 40 entrevistas, semiestruturadas, abertas, direcionadas aos sujeitos do estudo. No entanto, somente 21 participantes consentiram com a publicação de suas respostas na pesquisa (um do gênero masculino e vinte do gênero feminino). Embora houvesse a possibilidade de aumentar o quantitativo de indivíduos, percebemos que as respostas estavam saturadas.

\section{Transformações no mundo do trabalho e suas consequências para o trabalho em saúde}

O trabalho pode apresentar várias formas, naturezas e sentidos em determinado momento histórico e ordem societária. Mas sempre haverá movimentos de construção de relações sociais, determinando a produção e a reprodução social da humanidade. Neste sentido, o trabalho confere uma identidade, é uma condição para a subsistência do ser humano e para o desenvolvimento de qualquer sociedade. "Estudar o trabalho do servidor público é percebêlo enquanto parte do universo dessa categoria social, como resultado de trabalho humano vivo, heterogêneo e possível de ser transformador da realidade social" (SILVA, 2013, p. 76).

Para Antunes (2009), as transformações ocorridas no capitalismo, desde as últimas três décadas do século XX, promoveram profundas e marcantes modificações no mundo do trabalho. A influência neoliberal, a reestruturação produtiva, política, cultural e econômica promoveu significativas mutações que abalaram o mundo do capital, redesenhando novas modalidades de trabalho. Um deslocamento que é feito para dar maior flexibilidade às medidas do mercado, agora com exigências que determinam a qualidade total. Desta forma, o desejo pelo controle e poder sobre o capital resulta em trabalhadores isolados e distantes da relação com o trabalho, das singularidades e subjetividades que cercam o universo de ser trabalhador. São novos contingentes de homens e mulheres terceirizados, subcontratados e temporários. Uma tendência dotada de um caráter destrutivo, resultando na precarização do trabalho em escala global, que acaba também afetando fortemente os trabalhadores do setor estatal. "Metamorfoseiam-se as noções de tempo e de espaço e tudo isso muda, sobremaneira, o modo como o capital produz as mercadorias, sejam elas materiais ou imateriais, corpóreas ou simbólicas" (ANTUNES, 2009, p. 249).

Neste sentido, acreditamos que o processo que incide sobre o setor de saúde no estado do Rio de Janeiro — que hoje está em um estado caótico— longe de ser uma política isolada, faz parte de uma transformação estrutural da forma como o capital vem sendo organizado, inclusive nos setores de saúde, relatado pela literatura para outros países, como o Canadá (DAVID; CLOUTIER; LEDOUX, 2011), os EUA e Reino Unido (WADDAN, 2011) e diversos países da Europa (ANDRÉ; HERMANN, 2009). Na maioria dos casos descritos pela literatura (GUIMARÃES; CARVELHO, 2011), tem lugar o modelo de subcontratação por contingência, prática que visa reduzir custos e externalizar responsabilidades trabalhistas para as empresas contratadas. Impulsionado pelo período neoliberal, que favoreceu a valorização 
do capital e de geração da mais valia, a terceirização tornou-se um dos elementos centrais do atual processo de precarização do trabalho no Brasil, um fenômeno presente praticamente em todos os outros campos, setores e espaços de trabalho (ANTUNES, 2015).

No caso em tela, a terceirização dos diversos setores públicos estaduais na saúde iniciouse pelo Hospital Estadual Adão Pereira Nunes (HEAPN), foi a primeira grande unidade a introduzir as Organizações Sociais de Saúde (OSS) como o principal modelo de gestão na saúde no estado do Rio de Janeiro, adotada pelo ex-Governador Sérgio Cabral Filho. A partir de outubro de 2013, os servidores, foram substituídos por novos profissionais terceirizados. A ação de saída destes profissionais foi conduzida de forma autoritária, e, para alguns, sem negociação. Os servidores tentaram fazer alguma resistência, e, com apoio de várias bases sindicais, ocorreram algumas manifestações. Mas o interesse do mercado foi muito mais forte, obrigando os funcionários a aceitarem as transferências, como exemplo, a Superintendência de Perícia Médica e Saúde Ocupacional, órgão administrativo e burocrático. Se não concordassem, teriam duas possibilidades: pedir exoneração do cargo ou ficar à disposição na Secretaria Estadual de Saúde (SES). Esta por sua vez, poderia enviar o servidor para qualquer lugar dentro do estado.

Em outras unidades de saúde, o processo de transição foi menos agudo, os funcionários da Secretaria Estadual de Saúde (SES) foram até os hospitais, conversaram com os profissionais, e disponibilizaram uma lista com alguns locais para os quais poderiam se transferir. Embora a transição tenha sido feita de forma mais amena, os servidores descreveram os mesmos sentimentos, a rejeição e a desvalorização por parte do estado, e a ausência do interesse e participação da população.

Paulatinamente, a lógica pública e universalista do SUS cede espaço para a lógica empresarial das OSS e Fundações de Direito Privado. Túlio Franco (1998), ao analisar as Organizações Sociais, apresentou seis fundamentais razões que ferem o direito de cidadania atribuído ao SUS pela Constituição: 1- quebra do sistema, na forma concebida originalmente pelo SUS; 2- extinção do quadro de servidores públicos da saúde nos estabelecimentos gerenciados pelas Organizações Sociais; 3- gestão dos recursos humanos centralizadores e normativa; 4- a saúde deixa de ser um direito público e passa a ser assumida pelo mercado; 5-não há necessidade de um novo modelo de assistência; 6- as Organizações Sociais não valorizam o controle social.

O governo defende a terceirização dentro do serviço público, visando suprir as suas próprias deficiências, alegando ser uma estrutura administrativa menos burocrática que se torna mais ágil e flexível, pauta-se no argumento da melhor produtividade, mas oculta diversos aspectos que desvalorizam essa vertente. A forma de gestão hoje organizada na saúde pública de todo país veio a criar, igualmente, uma situação em que o custo e o benefício parecem ser mais importantes do que o respeito pelo direito dos cidadãos à saúde (NUNES, 2006).

Neste sentido, Fleury e Ouverney (2012) nos revelam que as políticas de saúde devem ser tratadas como política social, pois esta deve estar voltada para a reprodução dos indivíduos e das coletividades. Quando se consolida esse entendimento, as consequências são imediatas: os indivíduos tomam consciência do seu papel como cidadãos e dos seus direitos. A existência de uma comunidade política saudável é fundamental à compreensão do sentido de cidadania, vínculo jurídico e político, o que requer a participação consciente dos indivíduos na vida pública. 
Giovanella e Mendonça (2012) relatam que o direito à cidadania vem como condição de igualdade entre os indivíduos da mesma comunidade. A universalidade é a indistinção entre os cidadãos. A noção de prestação pública é decorrente da garantia do direito à cidadania e da ideia de saúde como bem público não comercializável, sendo o Estado a instituição correspondente. Por esse motivo, a presença dele na garantia do acesso universal à saúde, no controle e na regulação dos mecanismos que interferem na saúde dos indivíduos é um diferencial na busca por melhores condições de saúde.

As unidades públicas foram gradativamente negadas aos seus servidores. Foi o mundo coletivo desses funcionários, com os valores, culturas e seus ideais, que foram subitamente sequestrados e desqualificados. Existe uma vida coletiva que se estabelece ao longo do tempo no trabalho, que permite definir laços afetivos dentro e fora do trabalho. Portanto, a problemática remete ao ser trabalhador da saúde, pois as categorias foram atingidas na sua subjetividade, que envolvem o profundo prazer e a construção de um saber técnico. Os servidores, subjugados às transformações do capitalismo, agora baseado na flexibilidade, na mobilidade e na velocidade, alteraram suas rotinas e atividades profissionais. Para Linhart, "O trabalho moderno caracteriza-se por uma hiperpersonalização. Esta deu origem a uma fragilidade importante dos assalariados, que se manifesta por um forte sentimento de precariedade, mesmo quando o emprego é estável” (LINHART, 2014, p. 49).

\section{Disputas de projetos: as OSS na visão dos trabalhadores de saúde}

Atualmente, temos duas frentes de atuação que são antagônicas e disputam o ideário sobre o papel da saúde pública no país: uma frente que defende a ampliação e radicalização dos investimentos públicos no sistema universal e outra que aposta no desgaste deste modelo e que busca uma lacuna que possa ser preenchida pelos planos privados. Estamos diante de uma possibilidade concreta de desmonte do $\mathrm{SUS}^{3}$. Neste cenário, o sistema privado vai oferecendo formas complementares e tende a se expandir.

De acordo com a Lei número 6043, de 19 de setembro de 2011, as Organizações Sociais Saúde (OSS) terá seu próprio quadro de pessoal e autonomia para estabelecer seu próprio plano de carreira e salários. Essa medida atinge de modo contundente a organização da força de trabalho porque a fragmenta e a torna frágil para lutar por melhores condições de maneira universal e para defender as políticas sociais nas quais está inserida como trabalhador. Além disso, fere o Sistema Único de Saúde (SUS).

Com a concorrência entre empresas, o SUS estará à mercê da lei do mercado, o que agravará as desigualdades dos atendimentos. Os ataques aos princípios e aos valores do SUS também representam um ataque à democracia. Enquanto os defensores do SUS sempre primaram pela democracia e pelo controle social, nas Organizações Sociais o espaço para isso está muito reduzido.

Após a fase exploratória e durante o período de vivência no campo, iniciamos o questionário com essa temática. Procuramos identificar a opinião dos entrevistados sobre a privatização da saúde pública no estado do Rio de Janeiro (Como você analisa a privatização da saúde pública no estado do Rio de Janeiro?). A universalidade dos entrevistados (21) se mostrou contrária

3 A PEC aprovada no Congresso congela gastos sociais por 20 anos. Na Saúde, a perda acumulada será de 654 bilhões de reais, em um cenário de crescimento do PIB de $2 \%$ ao ano, segundo uma nota técnica divulgada pelo Instituto de Pesquisa Econômica Aplicada (Ipea). 
à privatização, sendo que o principal motivo se relaciona ao risco iminente de enfraquecer e desestabilizar os servidores, a população e o sistema público de saúde. A seguir, uma fala na qual ficam evidentes as indignações com a privatização da saúde:

Péssimo. Uma jogada política para se ganhar dinheiro, ninguém está preocupado com a população doente no hospital. O serviço não tem continuidade, acabaram os ambulatórios e visitas domiciliares para os idosos e deficientes físicos. Que política é essa que acaba com os direitos sociais? Na privatização hoje você tem uma gerência e amanhã tem outra, os contratos são temporários com o Estado, se não houver pagamento por parte do Estado, não tem pagamento para o trabalhador. Estão faltando muito aos plantões, porque também estão com salários atrasados, e infelizmente, é a população mais carente que perde, ou seja, todos os cidadãos estão perdendo, seja trabalhador ou paciente, só ganha quem tem o verdadeiro poder da caneta (Entrevista realizada em 11/05/16, assistente social).

Os trabalhadores concordaram que o Estado usou a força institucional e legal para implantar as Organizações Sociais de Saúde (OSS) e as Fundações de Direito Privado (FDP) e, portanto, estabelecem contratos de trabalhos diferenciados seguindo a lógica de cada empresa privada, nas quais predominam critérios de produtividade e qualidade estabelecidos pelas empresas. Relataram que as Organizações Sociais em Saúde (OSS) não se constituem como solução para resolver problemas de gestão e serviços no SUS.

Azevedo e Sá (2013) nos dizem que devemos compreender o trabalho em saúde como essencialmente intersubjetivo, "uma intervenção de um sujeito sobre outro, em suas experiências de vida, prazer, dor, sofrimento e morte" (AZEVEDO; SÁ, 2013, p. 42). Portanto, tais questões demandam imenso trabalho psíquico, físico e social, criando uma identidade própria.

Em seguida, questionou-se a identidade /subjetividade de ser servidor público da saúde (Como se configura a atual identidade do servidor da saúde pública do estado do RJ?). A quase totalidade (20) dos entrevistados relatou não se identificar com a atual atividade, e que as ações exercidas e compartilhadas com o coletivo no dia a dia no trabalho reforçam o distanciamento das práticas e subjetividades específicas a cada segmento profissional, como podemos observar no relato:

Perdeu-se a essência, muito frustrante. No hospital, você conhecia outros serviços, compartilhava o conhecimento. Vou morrer sentada nesta cadeira. Identidade profissional acabou quando os gestores tiraram das unidades os profissionais especializados, experientes e qualificados, para contratar recém-formados e ocupar o nosso lugar, todos perdem, o serviço, os servidores e os pacientes, só quem ganhou foi o governo (Entrevista realizada no dia 04/01/2016, técnica de enfermagem).

O perfil dos servidores recém-chegados na instituição (SPMSO) era de profissionais assistencialistas, todos profissionais do Sistema Único de Saúde, acostumados a atender e responsabilizar-se pelos usuários, e, na sua maioria, com décadas de trabalho em unidades específicas, como: CTI, UTI neonatal, central de esterilização, emergência geral, emergência pediátrica, emergência de otorrinolaringologia, bucomaxilofacial entre outros. Trata-se de setores que demandam treinamento e capacitação constantes, investimento e prática. De acordo com Azevedo e Sá (2013), existe uma especificidade no trabalho em saúde, que implica a probabilidade do envolvimento, de solidariedade e do cuidado. 
Durante o período no campo, observamos a expressão descrente de cada trabalhador, pois a conjuntura política, econômica e social no estado do Rio de Janeiro estava imersa em hostilidades contra os servidores. Estes se encontravam apáticos, passivos, isolados, somando, ao desânimo de trabalhar sem perspectivas, o sentimento do não lugar, de não pertencer àquele contexto. Esses sentimentos, somados aos desvios de função, vieram à tona quando responderam sobre o valor da atual atividade (Em que medida você definiria o valor da sua atual atividade?). Os participantes (21) responderam uniformemente, declararam que realizam atividades de menor valor e sem significado produtivo, quando comparado às atividades profissionais realizadas nas unidades hospitalares estaduais. Como o exemplo a seguir:

A enfermagem me deu tudo que tenho, ser enfermeira é o meu maior prazer, poder tocar e cuidar de ser humanos é um dom, aqui trabalhamos com papel, papel é papel. Eu ainda tenho a minha caixa de bilhetinhos que ganhava dos pacientes durantes anos em atividade, isso é ter valor, ser reconhecido pelo que se faz pelo outro. Isso aqui é frustrante, um pesadelo para quem gosta do cuidar (Entrevista realizada no dia 11/05/2016, enfermeira).

A desilusão e o descontentamento com a nova rotina de trabalho foram amplamente relatados, alguns participantes toleram estar na instituição porque não têm para onde ir, não suportam a ideia de voltar para as unidades gerenciadas pelas Organizações Sociais de Saúde e/ou pelas Fundações, e, na maioria, aguardam a possibilidade de uma vaga em uma unidade hospitalar em algum município próximo de sua residência.

A questão seguinte trouxe à tona o objeto autonomia, fundamental para a construção da identidade das categorias (No seu entendimento, existe autonomia para você realizar as atividades executadas?). Treze (13) participantes responderam que não havia liberdade para agir ou criar, são sujeitos ligados aos serviços que seguem obrigatoriamente um fluxo de trabalho. Oito (8) declaram ter autonomia, sendo estes, os profissionais com maior liberdade nas suas atividades, pois estão inseridos em setores independentes do fluxo institucional, como exemplo: o museu, o setor de recursos humanos, o setor de interiores.

Não. Impossível, estruturalmente esse sistema não permite inovar, ele segue um fluxo que não permite mudanças (Entrevista realizada no dia 14/06/2016, médico).

Para Antunes (2009), a atual configuração do trabalho se expressa por meio de um funcionário que não se satisfaz nas suas atividades, não se reconhece, e, assim, se desumaniza no trabalho. O sentido dado ao ato de trabalhar pelo capital é inteiramente diferente do sentido que o trabalhador pode conferir a ele.

Embasada nesta compreensão, a última questão procurou identificar o ponto de vista dos entrevistados sobre o contentamento no trabalho (Em sua opinião, você se realiza hoje com o seu trabalho no estado RJ?). Vinte (20) participantes se mostraram contrários a satisfação profissional. Sendo os principais motivos: a desvalorização do servidor, as perdas salariais, o desvio de função, a inflexibilidade institucional e a perda crescente das condições de trabalho.

Não. Falta respeito com todos que trabalharam muito para o estado e hoje estamos completamente desvalorizados, esquecidos neste lugar, sem vida, que enlouquece qualquer um que adora a saúde pública (Entrevista realizada em 02/05/16, enfermeira). 
Antunes (2009) afirma que o grande desafio da humanidade é dar sentido ao trabalho humano, o que supõe uma vida repleta de sentido fora do trabalho. "Uma vida desprovida de sentido no trabalho é incompatível com uma vida cheia de sentido fora do trabalho. Em alguma medida, a esfera do trabalho estará maculada pela desefetivação que se dá no interior da vida laborativa" (ANTUNES, 2009, p. 231, grifos do autor).

\section{Sofrimento, despersonalização, medo e ansiedade: dialogando com a literatura}

Foi essencial conhecer as histórias e trajetórias narradas pelos sujeitos, participar da rotina vivida no contexto dos serviços em saúde pública, considerando o espaço físico e as relações que influenciam as interpretações, os pensamentos, os sentimentos e as ações, a fim de abstrair os significados simbólicos e interpretar suas atitudes.

Durante os três anos de observação participante, vivenciamos momentos em que as expressões gestuais falavam por si mesmas. De quando em quando, os atores se entregavam pelo olhar, por vezes brilhantes, ao relembrarem de algumas conquistas e vitórias na assistência de usuários do serviço público. Quase a totalidade dos atores narrava as dificuldades de trabalho em um hospital público, onde sempre faltam insumos e recursos humanos, o que prejudica a operacionalidade do serviço. Ainda que enfrentando dificuldades para exercer suas atividades, eles mantinham uma unidade e uma identidade profissional.

Foram pressupostos desta pesquisa os relatos das experiências vividas pelos entrevistados, que nos revelam os sentimentos de "não estar em casa no trabalho"; de abandono, frieza e tristeza; de desvalor e inutilidade; de indiferença para com o outro, somente pequenos grupos são permitidos, e ainda, convivem com a gravidade das desigualdades entre as classes sociais; de isolamento; de insatisfação e uma falsa autonomia; de medo e insegurança no trabalho.

Os servidores convivem em constante "risco emocional" e trabalham no limite de suas possibilidades, como apontado por Linhart, "Os assalariados trabalham sempre o fio da navalha, sozinhos, sem o suporte e a ajuda operacional de coletivos solidários, sem poder compartilhar seus problemas, suas dificuldades, seu sofrimento" (LINHART, 2014, p. 50). Neste sentido, não existe a dimensão sagrada, moral, ética ou ideológica do trabalho.

A flexibilização no serviço público está seguindo a mesma lógica mercadológica que a iniciativa privada, a partir da legalização do serviço terceirizado, incluindo não só as chamadas atividades-meio, mas também as atividades-fim. Estes elementos na mudança organizacional foram incorporados ao serviço público e várias novas formas de trabalho vêm sendo regularmente adotadas em todos os estados do país. As Organizações Sociais e as Fundações de Direito Privado substituíram as cooperativas e eclodiram no período neoliberal no Brasil. $\mathrm{Na}$ saúde pública, houve uma "epidemia" de autogestores, autônomos, independentes e isolados do coletivo e dos direitos trabalhistas. Um dos exemplos mais consolidados no país são as Organizações Sociais de Saúde, que atuam fortemente na atenção primária e hospitalar. Outra estratégia utilizada desde os anos 90 são os terceirizados, vital para o capitalismo, estes são "prestadores de serviço, contratos eventuais, parciais, entre outros, representados pelo setor privado, que atua executando serviços de segurança, limpeza, jardinagem, lavanderia etc " (SILVA, 2013, p. 80), parceiros constantes dentro do serviço público, constituindo-se uma ruptura no processo de organização trabalho. 
Este novo formato do trabalho atinge diretamente os servidores públicos, que constroem e executam as políticas públicas, "estabelecem relações sociais e políticas dentro do estado e fora dele, interagindo e construindo um sentido do trabalho, pendular, criativo, alienante, produtivo, improdutivo, material e imaterial" (SILVA, 2013, p. 83).

Linhart (2014) relata que a precariedade subjetiva afeta muitos trabalhadores com empregos estáveis e funcionários públicos. São profissionais que sofrem com as constantes exigências e mudanças de planejamento dos gestores, gerando ansiedade e preocupações de não estarem em condições de responder às expectativas institucionais. O sentimento de precariedade subjetiva não permite que os trabalhadores se sintam protegidos ou seguros em seus empregos, embora pareça paradoxal sentir-se desta forma, considerando que são funcionários que possuem emprego estável, sem risco de serem demitidos, frente à grande massa de desempregados. Mas eles existem e "é no face a face solitário com o trabalho que estão condenados a encontrar soluções, que são permanentemente desafiados por objetivos cada vez mais exigentes, sem possibilidade de negociar os meios" (LINHART, 2014, p.51). Linhart define a precariedade subjetiva como:

É o sentimento de não estar "em casa" no trabalho, de não poder se fiar em suas rotinas profissionais, em suas redes, nos saberes e habilidades acumulados graças à experiência ou transmitidos pelos mais antigos; é o sentimento de não dominar seu trabalho e precisar esforçar-se permanentemente para adaptar-se, cumprir os objetivos fixados, não arriscar-se física ou moralmente (no caso de interações com usuários ou clientes). É o sentimento de não ter a quem recorrer em caso de problemas graves no trabalho, nem aos superiores hierárquicos (cada vez mais raros e cada vez menos disponíveis) nem aos coletivos de trabalho, que se esgarçaram com a individualidade sistemática da gestão dos assalariados e a concorrência entre eles. É sentimento de isolamento e abandono. (LINHART, 2014, p.45).

O trabalho, para Linhart (2007), é carregado de sentidos e significados além de ser o organizador dos encontros sociais. É um ótimo motivo para "quebrar" a monotonia do cotidiano, encher o vazio de si mesmo e dar um propósito ao tempo e à vida. O trabalho é sobretudo um "ordenador do tempo. Ao impor sua própria duração, ele anula, apaga o tempo que o indivíduo dedica a si mesmo. Tempo durante o qual não se sabe o que fazer" (LINHART, 2007, p. 43). O tempo livre só existe em oposição, em contraste com o período obrigatório das atividades profissionais. O indivíduo é direcionado para o trabalho devido à atual organização da sociedade. E como, na maior parte das vezes, não se pode viver sem o trabalho, "é preciso acomodar-se, adaptar-se a ele. Para ocupar seu tempo, para ocupar sua vida, é preciso aceitar ser tiranicamente espoliado” (LINHART, 2007, p. 46).

As estratégias modernas de gerenciamento, em que é conveniente manter um estado de excitação e insegurança no serviço público, promove instabilidade e medo entre os profissionais. Trata-se da tentativa empreendida pela administração de evitar que se reconstituam coletivos próprios dos trabalhadores, potencial para ações de resistência e de contestação dos assalariados. Eles sabem que estão sendo frequentemente avaliados, comparados e julgados; a exigência de excelência no trabalho e enfrentar o desafio e a capacidade de ir além, de provar que merecem o lugar que têm. "O fracasso torna-se catastrófico, e o medo de enfrentá-lo causa uma angústia real, o burnout [itálico do autor] e o assédio, assim como os suicídios, poderiam ser consequências dessa angústia" (LINHART, 2014, p.51). 
Essa nova tendência do trabalho torna o trabalhador cada vez mais desvalorizado. Perdemse, a cada dia, direitos constitucionalmente adquiridos e garantias sociais. As instituições públicas e privadas buscam formas modernas e disfarçadas de submeterem seus funcionários às mais diversas precarizações, sem qualquer garantia de continuidade. As intervenções são variadas e ignoram o contexto das relações. "O trabalhador precarizado se encontra, ademais, em uma fronteira incerta entre ocupação e não ocupação e em um não menos incerto reconhecimento jurídico diante das garantias sociais" (VASAPOLLO, 2005, p.10).

Linhart (2007) chama a atenção para dois cenários que vivemos atualmente no universo do trabalho, inicialmente distintos: o primeiro envolve os trabalhadores estáveis e ou servidores públicos, que perdem a cada dia a estabilidade psíquica e física. São agentes controlados e dominados por uma organização taylorista do trabalho, alocados para desenvolverem o trabalho prescrito. Este rapto do sentido do trabalho segue a lógica mercantil, a racionalidade econômica do capitalismo, impossibilita a autonomia, os vínculos, o sentimento de utilidade e a criação. Os trabalhadores seguem os novos valores e padrões institucionais, tornando-se trabalhadores amorfos. Como discorre Linhart, são "lógicas que podem levar a uma eterna precipitação da tensão e do estresse contínuo, ou ainda a atitudes individuais de distanciamento e também de revolta" (LINHART, 2007, p.122).

O segundo cenário avança de acordo com as inovações tecnológicas e no contexto das atuais inovações organizacionais, a nova fase é denominada "modernização do trabalho", período conhecido como pós-taylorista. No toyotismo, criam-se políticas inovadoras nas empresas, estimulam principalmente os jovens, exigindo: eficiência, praticidade, flexibilidade, autonomia e inteligência. Esta nova utopia, estimulada pelos Estados Unidos e pelo Japão, sustentava um compromisso e um futuro com a instituição que, ao mesmo tempo em que promovia o sofrimento e a injustiça social, "acenava com a promessa de felicidade, de identidade e de realização para os que soubessem adaptar-se a ela e contribuir substancialmente para seu sucesso e sua excelência” (DEJOURS, 2007, p.41).

Neste cenário, Antunes (2015) relaciona o atual desenho do trabalho com o aumento mundial dos acidentes, doenças profissionais e doenças ocupacionais relacionadas ao trabalho, em especial, as psicossociais, responsável por afastamentos de trabalhadores estáveis e precários, homens e mulheres, jovens e idosos, brancos, negros e índios, qualificados e desqualificados, entre tantos outros exemplos. Clot (2006) chama a atenção para um aspecto paradoxal no trabalho: há uma cobrança no cumprimento de responsabilidades, sem, contudo, disponibilizálas. Assim, o trabalho é reduzido à realização de procedimentos e perde seu sentido de utilidade. Nesta linha de pensamento, o trabalho pode contrariar sua ação e impedir as pessoas de trabalhar. "O sofrimento é uma atividade contrariada, um desenvolvimento impedido. É uma amputação do poder agir” (CLOT, 2006, p.5).

Linhart (2007) sinaliza que a possível origem dos processos de adoecimento psíquico, cada dia mais visível no cotidiano do trabalho, está associada ao crescente individualismo e ruptura dos laços sociais. Os ambientes marcados pela gestão flexível tendem a fragilizar a organização das estratégias coletivas de defesa entre os trabalhadores.

Dejours revela que as motivações subjetivas do consentimento relacionadas ao sofrimento no trabalho são decisivas para participação no sistema. "O sofrimento aumenta porque os que trabalham vão perdendo gradualmente a esperança de que a condição que hoje lhes é dada possa amanhã melhorar" (DEJOURS, 2007, p.17). Os trabalhadores, ao longo dos anos, vêm percebendo que o esforço, a dedicação e o sacrifício não estão sendo recompensados, 
mesmo que a cada dia tornem-se mais produtivos e competitivos. A relação com o trabalho vai progressivamente se distanciando do imaginário de felicidade e segurança, e não satisfaz as expectativas criadas na esfera material, afetiva, social e política.

Neste sentido, Dejours (2007) relata que o lado mais cruel do sofrimento está no vazio intelectual a que cada trabalhador está submetido. Com o passar dos anos, ele carrega toda a responsabilidade da sua angústia, levando-o à sensação permanente de impotência e incapacidade, em que seus conhecimentos acumulados são desconsiderados e inúteis. $\mathrm{O}$ reconhecimento é uma reivindicação legítima dos que trabalham. A partir dele, toda dedicação, angústia, medo, ansiedade, dúvida, receio adquirem sentido. $\mathrm{O}$ reconhecimento no trabalho fortalece a autoestima, tornando-se a base para a construção da identidade. Ele efetiva-se pelo prazer e pela alegria de fazer parte de um grupo social.

O autor ressalta que o trabalho é um elemento central na constituição da saúde e da identidade dos indivíduos adultos, e o principal elo entre tais indivíduos e a sociedade. O não comportamento ou reação pode gerar efeitos sobre a saúde mental, o que significa minimizar todos os aspectos subjetivos mobilizados no ato de trabalhar. Quando os trabalhadores enfrentam situações que limitam suas ações, pensamentos e desejos contrários aos das instituições, tem-se uma fonte de sofrimento. "A identidade constitui a armadura da saúde mental" (DEJOURS, 2007, p. 34).

A influência do medo na maioria dos trabalhadores desafia e aciona o conhecimento de inventividade para melhorar os resultados, na esfera qualitativa e quantitativa. Assim, a organização do trabalho se beneficia do medo do trabalhador, que precisa usar sua inteligência para se manter produtivo (DEJOURS, 1992).

\section{Considerações Finais: retomando o problema}

Quando iniciamos a pesquisa de campo não podíamos imaginar que haveria um atravessamento estrutural com tamanha força, se mostrando como um dos piores cenários do extremo conservadorismo na política, na economia, na história e no bem-estar social do país e do estado do Rio de Janeiro. Os servidores estaduais responderam às sequências de ataques e perdas promovidas pelas mudanças da condição institucional e governamental, que resultaram em: salários atrasados; contenções de despesas radicais; privatizações; perda das condições básicas de operacionalidade em diversas categorias, o fechamento frequente de setores essenciais, como as emergências das principais unidades de saúde e, ainda, o cenário do congelamento, por duas décadas, dos investimentos em saúde e educação.

Podemos concluir que as condições de trabalho vêm se tornando um elemento para o capital, por meio dos cenários do extremo conservadorismo na política, na economia, na história e no desmonte do estado de bem-estar social. A maioria dos participantes respondeu e demonstrou sentir-se despoja do sistema organizacional, e não acredita no crescimento da saúde pública. O estado se mostra indiferente aos processos identificatórios, que são desconfigurados pela exigência do cumprimento do papel de ser "servidor público". Existe uma indignação com o sistema, que fez com que eles fossem desvalorizados, ao serem destituídos das suas atividades, perderam autonomia e independência, desconfigurando sua identidade pessoal, profissional e social. Neste sentido, Bauman (2005) e Linhart (2007) atribuem a questão da identidade ao sentimento de pertencimento, assim como dos caminhos percorridos e a vontade de agir durante o processo. Assim sendo, a maioria dos servidores sentem-se deslocados e 
intrusos, não reconhecem a Perícia Médica como local de trabalho e crescimento profissional. Estão imersos na apatia, na passividade, no isolamento, na angústia de viver no não lugar, somando-se o desânimo de trabalhar sem perspectivas.

É possível perceber o paradoxo no sentido e significado do trabalho para este grupo analisado, as rupturas do cotidiano no trabalho promoveram sentimento de indignação, de isolamento, de ansiedade e medo do futuro quando poderia ser prazer e valorização profissional. Quando o trabalho deixa de ser transformador e promotor de qualidade de vida e torna-se adoecedor, depara-se com uma dualidade, precisar do trabalho porque ele agrega valor social e econômico. Assim, o trabalho é reduzido à realização de procedimentos e perde seu sentido de utilidade. Atualmente a representação do papel de ser servidor público da saúde, para a maioria do grupo analisado, é pela subsistência. Uma epidemia global, estando relacionada às diferentes exigências em que o homem contemporâneo precarizado está inserido.

As categorias foram atingidas na sua subjetividade, que envolvem o profundo prazer e a construção de um saber teórico e técnico. Os servidores, subjugados às novas transformações, baseadas na flexibilidade, na mobilidade e na velocidade, alteraram o cotidiano, as relações e os vínculos. Nessa perspectiva, o trabalho assume o papel organizador da vida social, pois ocupa papel central na formação da identidade do indivíduo, com espaço para dominação e submissão do trabalhador, mas, igualmente, de resistência, de construção e do fazer histórico.

De acordo com Pereira (2009), o Estado é um campo tenso e contraditório, no qual interesses diversos e opostos se confrontam. No contexto capitalista, coexistem tanto interesses representantes do capital quanto dos trabalhadores, com necessidade em partilhar da riqueza acumulada e participar do poder. Portanto, "O Estado é ao mesmo tempo uma relação de dominação, ou a expressão política da dominação de bloco no poder, e um conjunto de instituições mediadoras e reguladoras dessa dominação" (PEREIRA, 2009, p. 293).

Durante as entrevistas, vários funcionários mostraram suas trajetórias de vida dialogando com o trabalho, o prazer e o desprazer de estarem vivenciando uma experiência até então, única: a de profissionais da saúde pública, concursados, capacitados e treinados para cuidar do outro, em difentes dimensões, no entanto encontram-se em serviços burocráticos, tornaram-se num grupo sem identitade, sem prazer, sem valor e sem perspectiva.

\section{Referências}

ANDRÉ, Christiane; HERMANN, Christoph. Privatisation and Marketisation of Health Care Systems in Europe. In: FRANGAKIS, M.; HERMANN, C.; HUFFSCHMID, J.; LÓRÁNT, K.. (eds) Privatisation against the European Social Model. Palgrave Macmillan, London, 2009. p 129-144

ANTUNES, Ricardo L. C. Os sentidos do trabalho: ensaio sobre afirmação e a negação do trabalho. São Paulo: Boitempo, 2009 (Mundo do Trabalho).

ANTUNES, Ricardo L.C. A sociedade da terceirização total. Revista ABET, v.14, n.1, p. 6-14, 2015.

ANTUNES, Ricardo L.C.A; PRAUN, Luci. Sociedade dos adoecimentos no trabalho. Serviço Social \& Sociedade, São Paulo, n.123. p. 507-427, jul/set.2015.

AZEVEDO, C. S.; SÁ, M. C.(Org.) Subjetividade, Gestão e Cuidado em Saúde: abordagem da psicossociologia. Rio de Janeiro: Editora FIOCRUZ, 2013. 
BAUMANN, Zygunt. Identidade: entrevista a Benedetto Vecchi. Tradução: Carlos Alberto Medeiros. Rio de Janeiro: Zahar, 2005.

CLOT, Y. A função psicológica do trabalho. Petrópolis: Vozes, 2006.

DAVID, Helene; CLOUTIER, Esther; LEDOUX, Elise. Precariousness, work organization and occupational health: the case of nurses providing home care services in Quebec. Policy and Practice in Health and Safety, v. 9, n. 2, p. 27-46, 2011.

DEJOURS, Christophe. A loucura do trabalho: estudo de psicopatologia do trabalho, tradução de Ana Isabel Paraguay e Lúcia Leal Ferreira. 5. ed. São Paulo: Cortez - Oboré, 1992.

DEJOURS, Christophe. A banalização da injustiça social. Tradução de Luiz Alberto Monjardim. Rio de Janeiro: Editora FGV, 2007.

FLEURY, S.; OUVERNEY, A. M. Política de Saúde: uma política social. In: GIOVANELLA, Lígia; ESCOREL, S.; LOBATO, L. V. C.; NORONHA, J. C.; CARVALHO, A. L.(Org). Politicas e sistema de saúde no Brasil. Rio de Janeiro: Editora Fiocruz, 2012, p 25-57 (Cap.1).

FRANCO, Túlio Batista. As Organizações Sociais e o SUS. 1988. Disponível em: www.datasus. gov.br/cns/temas/as_organizações_sociais_e_osus.htm. Acesso em: 15 nov. 2014.

GIOVANELL, A. L.; MENDONÇA, M. H. Atenção primária à saúde. In: GIOVANELLA, L.; ESCOREL, S.; LOBATO, L. V. C.; NORONHA, J. C.; CARVALHO, A. L. (Org.) Políticas e Sistema de Saúde no Brasil. Rio de Janeiro: Ed. Fiocruz; 2012, p: 575-625. (Cap. 16).

GUIMARÃES, Cristina Machado; CARVALHO, José Crespo de. Outsourcing in the Healthcare Sector: A State of the Art. Review, Supply Chain Forum: An International Journal, v. 12, n. 2, p. 140-148, 2011.

LINHART, Danièle. A desmedida do capital. São Paulo: Boitempo, 2007.

LINHART, Danièle. Modernização e precarização da vida no trabalho. In: ANTUNES, R. Riqueza e miséria do trabalho no Brasil III(Org.) 1ºd. São Paulo: Boitempo, 2014.

LINHART, Danièle. La comédie humaine du travail: de la déshumanisation taylorienne à la sur-humanisation managériale.coll. Sociologie clinique. Paris:Erès, 2015.

NUNES, J.A (2006). A pesquisa em saúde nas ciências sociais e humanas. In: Congresso Mundial de Saúde Pública, 11², 2006, Rio de Janeiro. Anais...

PEREIRA, Potyara Amazoneida. Do estado social ao estado social de mal-estar. In: Politica social, trabalho e democracia em questão. Brasília: DPP/UNB, 2009.

SILVA, M. C. C. C. A saúde do servidor público em sua dimensão social. Maceió: EDUFAL, 2013. 325 p. VASAPOLLO, Luciano. O trabalho atípico e a precariedade. São Paulo: Expressão Popular, 2005.

WADDAN, Alex. The Politics and Changing Political Economy of Health Care in the US and the UK. In: Casey T. (eds). The Legacy of the Crash. Palgrave Macmillan: London, 2011,p 201-220. 